\title{
Kajian Metode Economic Order Quantity dan Reorder Point pada Aplikasi Point Of Sale
}

\author{
Raffa Ismunandar ${ }^{1}$, Ade Andri Hendriadi ${ }^{2}$ Garno $^{3 *}$ \\ 1,2,3 Jurusan Informatika, Fakultas Imu Komputer, Universitas Singaperbangsa Karawang \\ 1,2,3Jln. H.S. Ronggowaluyo Telukjambe Timur, Karawang, 41361, Indonesia \\ email: ${ }^{1}$ raffa.ismunandar@student.ac.id, ${ }^{2}$ ade.andri@staff.unsika.ac.id, ${ }^{3}$ garno@ @staff.unsika.ac.id
}

Received: 15 Mei 2018; Revised: 1 Oktober 2018; Accepted: 20 Oktober 2018

Copyright $\bigcirc 2018$, Politeknik Harapan Bersama, Tegal

\begin{abstract}
Inventory control can be said to increase the speed of work to achieve the level of energy efficiency and time in data management. Sales that have the transaction data still handwritten resulted in long enough time in recording the data, as well as the absence of determination of inventory and determining when the ordering of goods returned. Point of Sale Study with Economic Order Quantity (EOQ) and Reorder Point (RoP) Method will be used to overcome the problem, management of transaction data in which there are methods of calculating order quantity and reorder time can minimize operational cost and optimize inventory. The EOQ method is used as a stock inventory controller and the RoP method is used for warning notification to avoid negligence. Based on the result of the research, it can be concluded that Point of Sale Application with Economic Order Quantity and Reorder Point Method $90 \%$ accepted and able to overcome the problems that exist in Faranita Foam Store.
\end{abstract}

Abstrak - Pengendalian persediaan barang dapat dikatakan mampu meningkatkan kecepatan pekerjaan sehingga dicapai tingkat efisiensi tenaga dan waktu dalam pengelolaan data. Penjualan yang memiliki data transaksinya masih ditulis tangan mengakibatkan memerlukan waktu yang perlu dipertimbangkan dalam pencatatan data, serta belum adanya penentu persediaan barang dan penentu kapan dilaksanakannya pemesanan barang kembali menjadi permasalahan. Kajian point of sale dengan metode economic order quantity (EOQ) dan reorder point $(\mathrm{RoP})$ akan digunakan untuk mengatasi permasalan tersebut, pengelolaan data transaksi yang didalamnya terdapat metode perhitungan kuantitas pemesanan serta penentu waktu pemesanan kembali dapat meminimalisir biaya operasional dan mengoptimalkan persediaan barang. Metode $E O Q$ digunakan sebagai pengontrol persediaan stok barang dan metode $R o P$ dipergunakan untuk notifikasi peringatan agar tidak terjadi kelalaian. Berdasarkan hasil penelitian diperoleh kesimpulan bahwa kajian point of sale dengan menggunakan metode economic order quantity yang dikombinasikan dengan reorder point mencapai $90 \%$ diterima dan mampu mengatasi permasalahan yang ada pada Toko Faranita Foam.

Kata Kunci - Point of Sale, Economic Order Quantity (EOQ), Reorder Point (RoP), Persediaan Barang, Pemesanan kembali.

*) Coresponding Author: (Garno)

Email: garno@staff.unsika.ac.id

\section{PENDAHULUAN}

Kebutuhan informasi yang semakin meningkat [1]. Seiring dengan pesat kemajuan dan perkembangannya meningkat pula kemajuan teknologi dan inovasi [2]. Bidang penjualan juga banyak mengalami perkembangan. Penjualan yang maju tidak dapat lepas dari memiliki bayaknya data, baik data barang, data transaksi penjualan, data pesanan, data persediaan dan lain-lain. Data-data tersebut perlu dilakukan pengolahan agar menjadi informasi. Informasi yang baik dari representasi data memerlukan teknik pengolahan yang baik pula sehingga mencapai hasil yang baik. Sisi waktu juga diperlukan perhatian dalam pengolahan data sehingga informasi yang dihasilkan dapat lebih cepat. Di dalam data penjualan memerlukan pengelolaan data, pengontrolan transaksi, pengecekan persediaan stok barang dan juga data order barang kembali [3], semuanya ditujukan agar dapat mengurangi kesalahan pencatatan barang masuk dan barang keluar, mengurangi kesalahan perhitungan transaksi, mengurangi kesalahan pencatatan stok serta dapat mengoptimalkan pengorganisasian data seperti persediaan barang [4] artinya semua dalam pengendalian [5][6] karena kuantitas barang yang diorder sudah berdasakan perhitungan dan peramalan terlebih dahulu, Sehingga tidak ada barang yang tersimpan di gudang terlalu lama dan jika ada pembelian serta pesanan dapat teratasi dengan cepat.

Toko kasur busa inoac Faranita Foam yang berada di Perumahan Bumi Telukjambe Karawang memiliki sistem pembukuan yang secara singkat dapat dikatakan secara manual, hal ini yang menyebabkan kesulitan pengorganisasian data baik pengolahan, pencarian, atau yang lain. Teknik pembukuan manual/tulis tangan, membutuhkan banyak buku untuk dapat membedakan kategori barang, transaksi dan kategori pelanggan serta dari setiap buku tidak dapat secara otomatis menentukan pencatatan data stok barang [7], serta tidak dapat pula secara otomatis dalam penentuan kapan dilaksanakannya pemesanan kembali ke distributor atau pemasok, keterlambatan dalam pemesanan kembali/reorder, input data stok barang mengakibatkan penjualan menurun sampai pembuatan laporan juga kurang sesuai harapan [8]. Adapun pencatatan pembukuan secara manual di toko faranita kerap terjadi kesalahan perhitungan diantaranya yaitu kesalahan perhitungan barang masuk dan barang keluar mencapai $15 \%$ perbulan, terjadinya kesalahan 
perhitungan transaksi pada laporan mencapai $20 \%$ perbulan dan kesalahan dalam pencatatan stok barang mencapai $10 \%$ perbulan. Permasalahan lambannya proses pencatatan sampai laporan mengakibatkan seperti beberapa prosentase di atas dan berpotensi mengakibatkan kerugian finansial. Kelalaian pencatatan stok mengakibatkan tidak maksimal dalam mengontrol minimal stok yang harus ada guna melayani kebutuhan customer. Kelalaian ini mengakibatkan customer banyak yang kabur disebabkan karena stok barang pesanan mengalami kekurangan [9]. Maka pada tempat penelitian perlu dibuat sistem informasi untuk lebih memudahkan dan mempercepat transaksi dan untuk memperbarui cara dan langkah pendataan dari yang sebelumnya [10].

Teknik untuk mengatasi permasalahan baik tentang perhitungan barang masuk atau barang keluar pernah dilakukan dengan metode $E O Q$ untuk meminimumkan biaya persediaan bahan baku pada sisi kuantitas, frekuensi, biaya pembelian, biaya penyimpanan dan total inventori cost [11]. Sebagai notifikasi dalam sistem yang digunakan sebagai strategi media kontrol jumlah order menggunakan jenis peringatan reorder point [12] pemesanan ulang dapat diorder pada kondisi jumlah minimum stok aman dan dapat dilakukan pada awal waktu[13] artinya jumlah persediaan yang harus tetap ada pada saat pemesanan dilakukan disebut sebagai titik pesan kembali atau reorder point [14], pengolahan data stok sebagai model yang berguna untuk kolaborasi rantai pasokan barang, yang mempersingkat waktu, pendeteksian stok minimum dengan teknik pengelolaan yang baik dan pengiriman barang dapat terjadwal secara cepat sampai pengiriman ke pihak konsumen akan berdampak lebih efisien[15], maka pada penelitian ini yang menjadi tujuan adalah mengatasi persoalan diatas yaitu pengolahan data, pencarian data, penentuan stok dan mengatasi keterlambatan pengiriman dan order/penentuan pemesanan kembali.

\section{PENELITIAN YANG TERKAIT}

Penelitian yang membahas tentang Economic Order Quantity (EOQ) dan Reorder Point (ROP) (Rafliana, Trian, 2018) menuliskan bahwa EOQ adalah salah satu model yang sudah lama, diperkenalkan oleh F.W. Harris di tahun 1914, walaupun lebih dikenal dalam teknik pengendalian persediaan karena mudah penggunaanya tetapi penerapannya harus memperhatikan asumsi yang dipakai. EOQ merupakan jumlah atau besarnya pesanan yang dimiliki, jumlah ordering costs dan carrying costs per-tahun yang paling minimal dan kapan perusahaan harus memesan kembali agar perusahaan tidak sampai kehabisan bahan. ROP merupakan saat atau titik dimana harus diadakan pesanan lagi sedemikian rupa sehingga kedatangan atau penerimaan material yang dipesan adalah tepat pada waktu dimana persediaan diatas safety stock [16].

Penelitian sebelumnya (T. Iqbal, D.,dkk, 2017) membuat aplikasi managemen persediaan barang dengan menggunakan metode EOQ (Economic Order Quantity) dipergunakan dalam membuat keputusan sehingga kebutuhan akan bahan ataupun barang untuk keperluan kegiatan perusahaan baik produksi maupun penjualan dapat terpenuhi secara optimal dengan resiko yang sekecil mungkin. Persediaan yang terlalu besar (over stock) merupakan pemborosan karena menyebabkan terlalu tingginya beban-beban biaya guna penyimpanan dan pemeliharaan selama penyimpanan di gudang. Hasil dari penelitian merupakan aplikasi persediaan dengan metode EOQ Probabilistik yang dengan menitikberatkan hasil dengan bentuk grafik untuk mempermudah pemilik perusahaan dalam mengambil keputusan [17].

Pengendalian persediaan bahan baku kain kemeja (Nissa, Khoirun, 2017) untuk menyelesaikan permasalahan tentang keterlambatan datangnya bahan baku selama 4 hari. Penelitian menggunakan metode $E O Q$ untuk mengetahui total biaya persediaan. Data yang digunakan pada penelitian yaitu jumlah pembeliaan bahan baku, jumlah penggunaan bahan baku, biaya simpan, biaya pemesanan, lead time dan frekuensi pemesanan. Hasil yang diperoleh dari metode $E O Q$ yaitu terjadi perbaikan pada pembelian bahan baku, total biaya persediaan bahan baku, frekuensi pemesanan, safety stock dan reorder point [18].

EOQ (Economic Order Quantity) dapat diterapkan pada penjualan yang dihubungkan dengan sistem atau sering diistilahkan dengan point of sale atau disingkat POS, (F. Nurcahyono, 2012), mengutip dari penelitian sebelumnya bahwa POS (point of sale) adalah kegiatan yang berorientasi pada penjualan serta sistem yang membantu proses transaksi. Penjualan sendiri memiliki pengertian dari berbagai literatur sebelumnya bahwa penjualan merupakan sebuah proses dimana kebutuhan pembeli dan kebutuhan penjualan dipenuhi, melalui antar pertukaran informasi dan kepentingan" [19]. Proses penjualan barang akan lebih baik jika semua yang berkaitan dengan kebutuhan customer selalu ada, apalagi berkaitan dengan barang yang laris dipasaran, sehingga perlu dilakukan pengawasan yang ekstra terutama jumlah stok barang atau sistem kontrol stok yang laris tersebut, karena jika customer membutuhkan barang dan toko tidak dapat memenuhi maka customer akan kecewa.

Penelitian tentang pengontrolan stok barang yang dapat melihat jumlah minimum stok barang (T. Lukmana, 2015) metode Economic Order Quantity (EOQ). Metode EOQ merupakan metode yang digunakan untuk mencapai tingkat persediaan yang seminimum mungkin, biaya rendah dan mutu yang lebih baik. metode ini digunakan untuk menghitung minimasi total biaya persediaan berdasarkan tingkat kurva biaya penyimpanan dan biaya pemesanan. Namun pada dasarnya metode ini berusaha mencari jawaban optimal dalam menentukan jumlah ukuran pemesanan ekonomis, titik pemesanan kembali (Reorder Point), dan jumlah cadangan pengamanan (Safety Stock) [9], maksudnya adalah persediaan tambahan yang diadakan untuk melindungi atau menjaga kemungkinan terjadinya kekurangan bahan (stock out) [20].

Reorder point memiliki beberapa faktor, adapun faktor tersebut yang mempengaruhi titik pemesanan kembali. Faktor tersebut diantaranya adalah Lead Time yaitu waktu yang dibutuhkan antara barang yang dipesan hingga sampai diperusahaan, Tingkat pemakaian bahan baku rata-rata persatuan waktu tertentu, Persediaan Pengaman (Safety Stock), yaitu jumlah persediaan barang minimum yang harus dimiliki oleh perusahaan untuk menjaga kemungkinan keterlambatan datangnya bahan baku [21].

Penghitungan reorder point dapat dihitung dengan rumus berikut:

RoP = Safety Stock + Kebutuhan selama Lead time 


\section{Keterangan:}

- $\mathrm{RoP}=$ Reorder point .

- Safety Stock = stok pengaman yang di tentukan oleh perusahaan.

- Kebutuhan selama Lead time = waktu tunggu $\mathrm{x}$ kebutuhan per hari.

Stok barang kerap sekali disebut-sebut sebagai persediaan atau dalam bahasa asing sering disebut inventory, Persediaan adalah kekayaan lancar yang terdapat dalam perusahaan dalam bentuk persediaan bahan mentah (bahan baku/raw material), barang setengah jadi (work in process), dan barang jadi (finished goods)[11]. Pengontrolan stok minimum dengan metode $E O Q$ dapat digunakan sebagai teknik pengendalian persediaan yang meminimalkan total biaya pemasanan dan penyimpanan[22]. Besarnya $E O Q$ dapat ditentukan dengan cara:

$$
\mathrm{EOQ}=\frac{\sqrt{2 D C_{o}}}{C_{u} i}
$$

Keterangan:

$D$ : Jumlah ( dalam unit ) yang dibutuhkan selama satu periode tertentu.

$C_{o}$ : Biaya pemesanan setiap kali pesan

$C_{u}$ : Harga Unit yang dibayar

$i$ : Biaya penyimpanan dan pemeliharaan di gudang dinyatakan dalam presentase dari nilai rata-rata dalam rupiah dari persediaan.

Pembelian berdasarkan economic order quantity terdapat syarat-syarat yang harus dipenuhi yaitu yang pertama harga pembelian bahan perunit constant, yang kedua setiap saat membutuhkan bahan baku selalu tersedia di pasar, yang ketiga jumlah produksi yang menggunakan bahan baku tersebut stabil yang berarti kebutuhan bahan baku mentah relative stabil sepanjang tahun.

\section{METODE PENELITIAN}

\section{A. Analisis Kebutuhan Kajian}

Klasifikasi dilakukan pada barang yang akan dianalisis yaitu kasur busa beserta aksesorisnya, adapun tabel tersebut ada beberapa kolom.

1) Menginventarisir data barang dalam tabel 1 sebagai bahan kajian.

2) Kolom nomor (No) sebagai item yang menjelaskan urutan barang yang berada pada toko Faranita Foam.

3) Kolom Item untuk mendeskripsikan nama dan tipe barang.

4) Kolom harga merupakan biaya unit setiap barang.

5) Kolom kebutuhan merupakan kuantitas atau volume barang tahunan.

6) Simulasi perhitungan mengambil data baris ke 7 sebagai contoh menghitung secara manual.

7) Tabel berikutnya merupakan hasil rekap perhitungan dari setiap barisnya item barang secara manual.

Implementasi direalisasikan pada Tabel 1 sebagai bahan kajian untuk dihitung secara manual. Adapun data kasur setiap item yang memiliki ukuran dan harga serta kebutuhan dalam pertahun.

\section{B. Analisis Metode}

Implementasi dari aplikasi point of sale dapat digambarkan seperti Gbr.1 yaitu garis besar aplikasi point of sale yang dipergunakan untuk mengatur pemrosesan item barang dengan model kontrol stok berdasarkan pemesanan dengan menggabungkan metode economic order quantity dan reorder point. Adapun metode dapat di gambarkan pada Gbr.1.

TABEL I

DATA ITEM BARANG DAN KEBUTUHAN

\begin{tabular}{|c|c|c|c|}
\hline No & Nama Barang & Harga & $\begin{array}{l}\text { Kebut- } \\
\text { uhan }\end{array}$ \\
\hline 1. & Kasur 180x30 & Rp. 1.800.000,- & 100 \\
\hline 2. & Kasur 160x30 & Rp. 1.600.000,-- & 100 \\
\hline 3. & Kasur $145 \times 30$ & Rp. 1.450.000,-- & 50 \\
\hline 4. & Kasur 120x30 & Rp. 1.250.000,-- & 100 \\
\hline 5. & Kasur 100x30 & Rp. 1.050.000,-- & 35 \\
\hline 6. & Kasur 90x30 & Rp. $950.000,-$ & 40 \\
\hline 7. & Kasur 180x20 & Rp. 1.200.000,- & 500 \\
\hline 8. & Kasur 160x20 & Rp. 1.100.000,- & 500 \\
\hline 9. & Kasur $145 \times 20$ & Rp. 1.000.000,- & 250 \\
\hline 10. & Kasur 120x20 & Rp. $\quad 850.000,--$ & 250 \\
\hline 11. & Kasur 100x20 & $\begin{array}{ll}\text { Rp. } & 750.000,-\end{array}$ & 150 \\
\hline 12. & Kasur 90x20 & Rp. $\quad 650.000,--$ & 200 \\
\hline 13. & Kasur 180x15 & Rp. $\quad 950.000,--$ & 150 \\
\hline 14. & Kasur 160x15 & Rp. $\quad 850.000,-$ & 150 \\
\hline 15. & Kasur $145 \times 15$ & Rp. $\quad 750.000,--$ & 100 \\
\hline 16. & Kasur 120x15 & Rp. $\quad 650.000,-$ & 120 \\
\hline 17. & Kasur 100x15 & Rp. $\quad 600.000,-$ & 80 \\
\hline 18. & Kasur 90x15 & Rp. $\quad 550.000,-$ & 150 \\
\hline 19. & Kasur $180 \times 10$ & Rp. $\quad 650.000,--$ & 200 \\
\hline 20. & Kasur $160 \times 10$ & Rp. $\quad 600.000,--$ & 200 \\
\hline 21. & Kasur $145 \times 10$ & Rp. $\quad 550.000,-$ & 50 \\
\hline 22. & Kasur $120 \times 10$ & $\begin{array}{ll}\text { Rp. } & 500.000,- \\
\end{array}$ & 200 \\
\hline 23. & Kasur 100x10 & Rp. $\quad 475.000,-$ & 50 \\
\hline 24. & Kasur 90x10 & Rp. $\quad 450.000,-$ & 100 \\
\hline
\end{tabular}

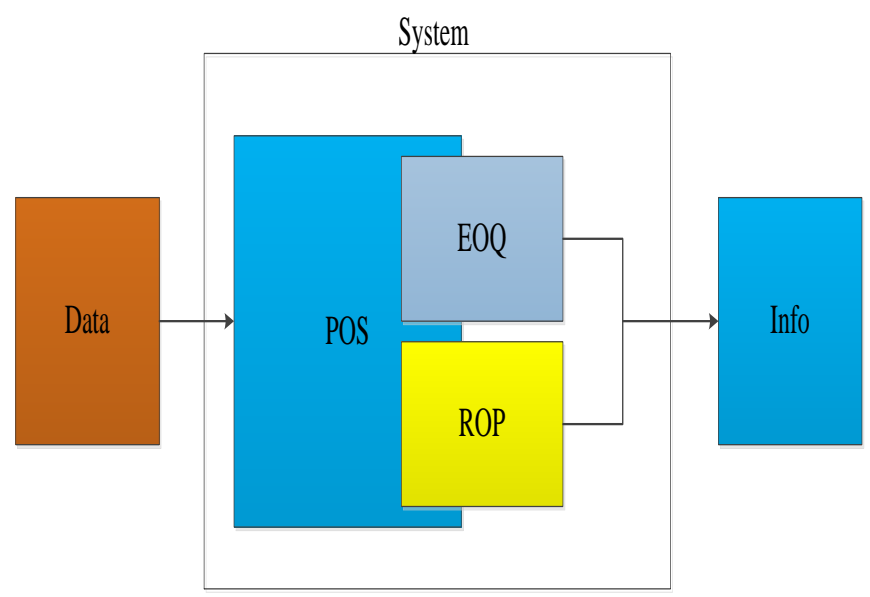

Gbr. 1 Metode Point of Sale pada aplikasi. 
Pada Gbr. 1 diatas bahwa data barang dari berbagai tipe ukuran diinput ke dalam aplikasi yang memiliki kemampuan secara $E O Q$ artinya dapat mengontrol stok terkecil pada batas limit yang ditentukan, jika kondisi barang terjual terus berjalan maka kondisi stok barang akan mencapai jumlah terkecil yang diatur, hal ini dikontrol oleh $E O Q$ dan jika mencapai nilai jumlah minimal, maka $R o P$ akan memberikan notifikasi sebagai peringatan bahwa diperlukan order barang kembali untuk menambah.

\section{Analisis EOQ dan RoP}

Dari data barang yang telah dijabarkan pada tabel 1 diatas ada juga biaya-biaya lain seperti biaya penunjang untuk perhitungan metode $E O Q$ yaitu biaya pemesanan setiap kali memesan serta biaya pemeliharaan per item barang. Perhitungan $E O Q$ sebagai contoh mengambil data kasur berukuran 180 x 20 pada tabel baris ke 7, adapun perhitungannya adalah sebagai berikut:

Holding Cost $=50 \%$ dari harga barang

Ordering Cost $=$ Rp. 50.000,- per pemesanan

Lead time $=2$ Hari

Jumlah Hari kerja $=320$ Hari.

Berikut rumus contoh perhitungan metode Economic Order Quantity dan Reorder Point secara manual untuk perhitungan item barang kasur baris ke 7 pada tabel 1 ditas yang berukuran $180 \times 20 \mathrm{~cm}$ :

$$
\begin{aligned}
\text { EOQ } & =\sqrt{\frac{2 D C_{o}}{C_{u} i}} \\
& =\sqrt{\frac{2 \times 500 \times 50000}{1200000 \times 50 \%}} \\
& =9,128709292 \text { Unit } \\
& =9 \text { Unit (pembulatan) }
\end{aligned}
$$

Untuk menghitung jumlah pemesanan barang adalah:

$$
\begin{aligned}
& =\frac{\text { Jumlah kebutuhan } 1 \text { tahun }}{\text { EOQ }} \\
& =\frac{500}{9} \\
& =55,56 \text { kali Pemesanan } \\
& =56 \text { Kali pemesanan (dibulatkan) }
\end{aligned}
$$

Sebelum menghitung Reorder Point terlebih dahulu mencari kuantitas pemakaian perhari dengan cara membagi total kebutuhan per tahun atau per periode dengan jumlah hari kerja per tahun. Lebih jelasnya lihat hasil perhitungan berikut:

$$
\begin{aligned}
\text { Kuantitas pemakaian }= & \frac{\text { Jumlah kebutuhan } 1 \text { tahun }}{\text { Jumlah Hari Kerja }} \\
& =\frac{500}{320} \\
& =1,5625 \\
& =2(\text { dibulatkan })
\end{aligned}
$$

berarti kebutuhan perhari 2 pcs.

untuk kasur yang berukuran 180 x $20 \mathrm{~cm}$ perusahaan menetapkan jumlah persediaan minimum sebanyak $10 \mathrm{pcs}$ dan diketahui bahwa waktu tunggu atau lead time selama 2hari serta kuantitas rata rata pemakaian perhari adalah 2 pcs bisa lebih dan bisa kurang.

Reorder Point untuk keadaan tersebut adalah:

$$
\begin{aligned}
\text { Reorder Point } & =\text { Safety Stock }+ \text { Kebutuhan selama Lead time } \\
& =10+(2 \times 2) \\
& =14
\end{aligned}
$$

Maka dapat disimpulkan bahwa untuk kasur yang berukuran 180x20 cm hasil dari perhitungannya ialah:

$$
\begin{array}{ll}
\text { EOQ } & =9 \text { PCS } \\
\text { Jumlah pemesanan } & =56 \text { Kali Pemesanan } \\
\text { Reorder Point } & =14 \\
\text { Safety Stock } & =10
\end{array}
$$

\section{Tahapan Penelitian}

Adapun langkah-langkah dalam menyelesaikan permasalahan menggunakan metode prototype sebagaimana Gbr berikut;

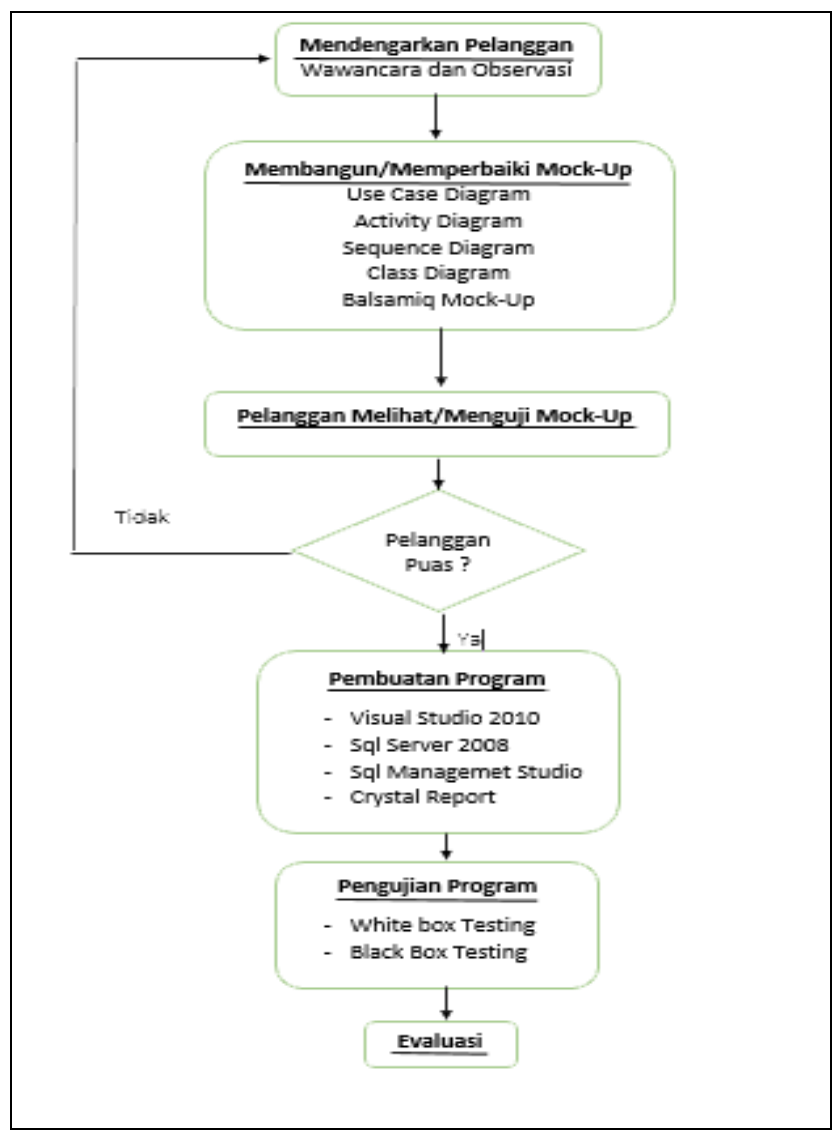

Gbr. 2 Tahapan penelitian

Tahap awal dari hasil wawancara dan observasi memperoleh analisis, kebutuhan baik fungsional dan nonfungsional. Berikutnya membuat desain mock-up dan revisi mock-up sampai pelanggan atau pemesan program merasa sesuai pesanan, barulah membuat program sesuai desain mock-up yang tersetujui, setelah program selesai 
dilakukan pengujian program baik secara user testing sampai baris program dan terakhir dilakukan evaluasi.

\section{HASIL DAN PEMBAHASAN}

Pembahasan penelitian dan pengujian yang dilakukan pada data bahan untuk uji guna penentuan pemesanan secara ekonomis serta penentuan waktu untuk melakukan pemesanan kembali yaitu data item barang beserta harga setiap jenis berdasarkan ukuran dan data rata-rata kebutuhan setiap itemnya, diperlihatkan pada Tabel II.

TABEL II

DATA HASIL PERHITUNGAN KEBUTUHAN PER-ITEM BARANG DENGAN EOQ DAN ROP UNTUK SELURUH ITEM BARANG

\begin{tabular}{|c|c|c|c|}
\hline NO & Nama barang & Harga & $\begin{array}{l}\text { Kebut- } \\
\text { uhan }\end{array}$ \\
\hline 1. & Kasur 180x30 & Rp 1.800 .000 & 120 \\
\hline 2. & Kasur $160 \times 30$ & Rp 1.600.000 & 120 \\
\hline 3. & Kasur $145 \times 30$ & Rp 1.450 .000 & 50 \\
\hline 4. & Kasur 120x30 & Rp 1.250.000 & 100 \\
\hline 5. & Kasur 100x30 & Rp 1.050 .000 & 35 \\
\hline 6. & Kasur 90x30 & $\begin{array}{ll}\mathrm{Rp} & 950.000\end{array}$ & 40 \\
\hline 7. & Kasur $180 \times 20$ & $\operatorname{Rp} 1.200 .000$ & 500 \\
\hline 8. & Kasur 160x20 & Rp 1.100 .000 & 500 \\
\hline 9. & Kasur $145 \times 20$ & $\mathrm{Rp} 1.000 .000$ & 250 \\
\hline 10. & Kasur 120x20 & Rp $\quad 850.000$ & 250 \\
\hline 11. & Kasur 100x20 & Rp 750.000 & 150 \\
\hline 12. & Kasur 90x20 & $\begin{array}{ll}\mathrm{Rp} & 650.000 \\
\end{array}$ & 200 \\
\hline 13. & Kasur 180x15 & $\begin{array}{ll}\mathrm{Rp} & 950.000 \\
\end{array}$ & 150 \\
\hline 14. & Kasur 160x15 & Rp $\quad 850.000$ & 150 \\
\hline 15. & Kasur $145 \times 15$ & $\begin{array}{ll}\mathrm{Rp} & 750.000 \\
\end{array}$ & 100 \\
\hline 16. & Kasur 120x15 & Rp $\quad 650.000$ & 120 \\
\hline 17. & Kasur 100x15 & Rp $\quad 600.000$ & 80 \\
\hline 18. & Kasur 90x15 & Rp 550.000 & 150 \\
\hline 19. & Kasur 180x10 & Rp $\quad 650.000$ & 200 \\
\hline 20. & Kasur 160x10 & Rp $\quad 600.000$ & 200 \\
\hline 21. & Kasur $145 \times 10$ & Rp 550.000 & 50 \\
\hline 22. & Kasur 120x10 & $\begin{array}{ll}\mathrm{Rp} & 500.000\end{array}$ & 200 \\
\hline 23. & Kasur 100x10 & Rp 475.000 & 50 \\
\hline 24. & Kasur 90x10 & Rp 450.000 & 100 \\
\hline
\end{tabular}

TABEL III

DATA HASIL PERHITUNGAN EOQ DAN DIBULATKAN UNTUK SELURUH ITEM BARANG

\begin{tabular}{|c|c|c|c|}
\hline NO & Nama barang & EOQ & $\begin{array}{l}\text { Pembu- } \\
\text { latan }\end{array}$ \\
\hline 1. & Kasur 180x30 & 3,65148372 & 4 \\
\hline 2. & Kasur 160x30 & 3,87298335 & 4 \\
\hline 3. & Kasur $145 \times 30$ & 2,62612866 & 3 \\
\hline 4. & Kasur 120x30 & 4 & 4 \\
\hline 5. & Kasur 100x30 & 2,5819889 & 3 \\
\hline 6. & Kasur 90x30 & 2,901905 & 3 \\
\hline 7. & Kasur 180x20 & 9,12870929 & 9 \\
\hline 8. & Kasur 160x20 & 9,53462589 & 10 \\
\hline 9. & Kasur $145 \times 20$ & 7,07106781 & 7 \\
\hline 10. & Kasur 120x20 & 7,66964989 & 8 \\
\hline 11. & Kasur 100x20 & 6,32455532 & 6 \\
\hline 12. & Kasur 90x20 & 7,84464541 & 8 \\
\hline 13. & Kasur 180x15 & 5,61951487 & 6 \\
\hline
\end{tabular}

\begin{tabular}{|c|c|c|c|}
\hline 14. & Kasur 160x15 & 5,94088526 & 6 \\
\hline 15. & Kasur $145 \times 15$ & 5,16397779 & 5 \\
\hline 16. & Kasur 120x15 & 6,0764362 & 6 \\
\hline 17. & Kasur 100x15 & 5,16397779 & 5 \\
\hline 18. & Kasur 90x15 & 7,38548946 & 7 \\
\hline 19. & Kasur 180x10 & 7,84464541 & 8 \\
\hline 20. & Kasur $160 \times 10$ & 8,16496581 & 8 \\
\hline 21. & Kasur $145 \times 10$ & 4,26401433 & 4 \\
\hline 22. & Kasur 120x10 & 8,94427191 & 9 \\
\hline 23. & Kasur 100x10 & 4,58831468 & 5 \\
\hline 24. & Kasur 90x10 & 6,66666667 & 7 \\
\hline
\end{tabular}

TABEL IV

DATA JUMLAH PEMESANAN DAN PEMBULATAN UNTUK SETIAP ITEM BARANG

\begin{tabular}{|c|c|c|c|}
\hline NO & Nama barang & $\begin{array}{l}\text { Jumlah } \\
\text { Pemesanan }\end{array}$ & $\begin{array}{l}\text { Pembu- } \\
\text { latan }\end{array}$ \\
\hline 1. & Kasur 180x30 & 30 & 30 \\
\hline 2. & Kasur 160x30 & 30 & 30 \\
\hline 3. & Kasur $145 \times 30$ & 16,66666667 & 17 \\
\hline 4. & Kasur 120x30 & 25 & 25 \\
\hline 5. & Kasur 100x30 & 11,66666667 & 12 \\
\hline 6. & Kasur 90x30 & 13,33333333 & 13 \\
\hline 7. & Kasur 180x20 & 55,55555556 & 56 \\
\hline 8. & Kasur 160x20 & 50 & 50 \\
\hline 9. & Kasur $145 \times 20$ & 35,71428571 & 36 \\
\hline 10. & Kasur 120x20 & 31,25 & 31 \\
\hline 11. & Kasur 100x20 & 25 & 25 \\
\hline 12. & Kasur 90x20 & 25 & 25 \\
\hline 13. & Kasur 180x15 & 25 & 25 \\
\hline 14. & Kasur 160x15 & 25 & 25 \\
\hline 15. & Kasur $145 \times 15$ & 20 & 20 \\
\hline 16. & Kasur 120x15 & 20 & 20 \\
\hline 17. & Kasur 100x15 & 16 & 16 \\
\hline 18. & Kasur 90x15 & 21,42857143 & 21 \\
\hline 19. & Kasur 180x10 & 25 & 25 \\
\hline 20. & Kasur 160x10 & 25 & 25 \\
\hline 21. & Kasur $145 \times 10$ & 12,5 & 13 \\
\hline 22. & Kasur 120x10 & 22,22222222 & 22 \\
\hline 23. & Kasur 100x10 & 10 & 10 \\
\hline 24. & Kasur 90x10 & 14,28571429 & 14 \\
\hline
\end{tabular}

TABEL V

DATA SAFETY STOK DAN ROP UNTUK SEMUA ITEM BARANG

\begin{tabular}{|l|l|c|c|}
\hline NO & Nama barang & Safety stock & RoP \\
\hline 1. & Kasur $180 \times 30$ & 5 & 9 \\
\hline 2. & Kasur $160 \times 30$ & 5 & 9 \\
\hline 3. & Kasur $145 \times 30$ & 3 & 7 \\
\hline 4. & Kasur $120 \times 30$ & 3 & 7 \\
\hline 5. & Kasur $100 \times 30$ & 2 & 6 \\
\hline 6. & Kasur $90 \times 30$ & 2 & 6 \\
\hline 7. & Kasur $180 \times 20$ & 10 & 14 \\
\hline 8. & Kasur $160 \times 20$ & 10 & 14 \\
\hline 9. & Kasur $145 \times 20$ & 8 & 12 \\
\hline 10. & Kasur $120 \times 20$ & 8 & 12 \\
\hline 11. & Kasur $100 \times 20$ & 6 & 10 \\
\hline 12. & Kasur $90 \times 20$ & 7 & 11 \\
\hline 13. & Kasur $180 \times 15$ & 6 & 10 \\
\hline
\end{tabular}




\begin{tabular}{|l|l|c|c|}
\hline 14. & Kasur $160 \times 15$ & 6 & 10 \\
\hline 15. & Kasur $145 \times 15$ & 5 & 9 \\
\hline 16. & Kasur $120 \times 15$ & 5 & 9 \\
\hline 17. & Kasur $100 \times 15$ & 4 & 8 \\
\hline 18. & Kasur $90 \times 15$ & 6 & 10 \\
\hline 19. & Kasur $180 \times 10$ & 7 & 11 \\
\hline 20. & Kasur $160 \times 10$ & 7 & 11 \\
\hline 21. & Kasur $145 \times 10$ & 3 & 7 \\
\hline 22. & Kasur $120 \times 10$ & 7 & 11 \\
\hline 23. & Kasur $100 \times 10$ & 2 & 6 \\
\hline 24. & Kasur $90 \times 10$ & 3 & 7 \\
\hline
\end{tabular}

Setelah dilakukan kajian secara manual dari seluruh data pada Tabel I didapatkan hasil perhitungan EOQ dan RoP. Keseluruhan untuk rekap hasil perhitungan setiap item barang kasur pada setiap ukuran yang ada dapat dilihat pada Tabel 3 dan Tabel 5.

Pada penelitian perancangan aplikasi terlebih dahulu dibuat desain use case untuk dapat melihat proses secara garis besar bahwa aplikasi dapat dipergunakan apa saja. Adapun desain use case pada aplikasi point of sale yang menggunakan metode $E O Q$ dan $R o P$ sebagai bentuk interaksi pengguna terhadap aksi pengelolaan pada aplikasi adalah pada Gbr.3.

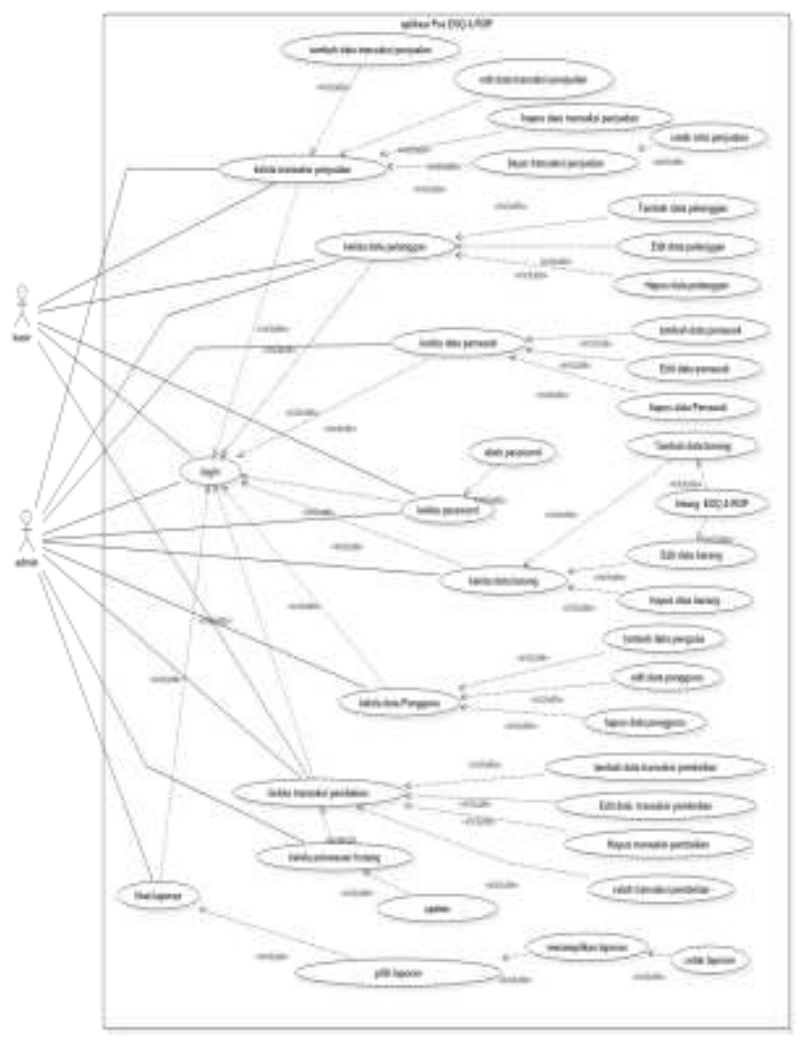

Gbr. 3 Use case Aplikasi point of sale

Pada Gbr 3, use case terdapat hubungan antara aplikasi dan pengguna, untuk pengguna dalam penelitian ini dibedakan menjadi dua yaitu user/kasir dan admin. Bagi user aplikasi dapat dipergunakan untuk melalukan hal-hal diantaranya mengelola transaksi penjualan, mengelola transaksi pembelian, mengelola data pelanggan. Bagi admin aplikasi dapat digunakan untuk mengelola transaksi penjualan, mengelola transaksi pembelian, mengelola data pelanggan, mengelola data pemasok, mengelola data barang, mengelola data pengguna aplikasi, mengelola data pelunasan hutang, mengelola laporan.

Agar aplikasi dapat menampilkan atribut yang dibuat sesuai dengan use case maka dibuatlah relasi antar tabel, adapun relasi tersebut adalah sebagai berikut;

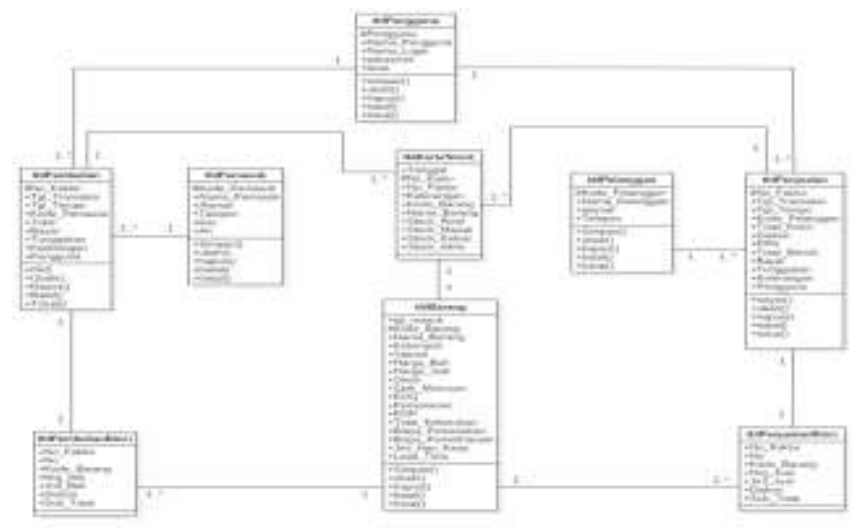

Gbr. 4 Class Diagram

Gbr. 4 class diagram diatas sebagai gambaran relasi antar tabel diantaranya yaitu tabel pengguna berelasi dengan tabel pembelian dan tabel penjualan, tabel kartu stok berelasi dengan tabel pembelian, tabel penjualan, tabel barang. Tabel barang sendiri berelasi dengan tabel penjualan rinci dan tabel pembelian rinci, dan tentunya tabel pembelian rinci berelasi dengan tabel pembelian. Tabel penjualan rinci berelasi dengan tabel penjualan. Adapun tampilan sebagai antarmuka agar pengguna dapat menggunakan aplikasi seperti pada Gbr.5, Gbr.6, Gbr.7, Gbr.8, Gbr.9, Gbr.10, Gbr.11, dan Gbr.12.

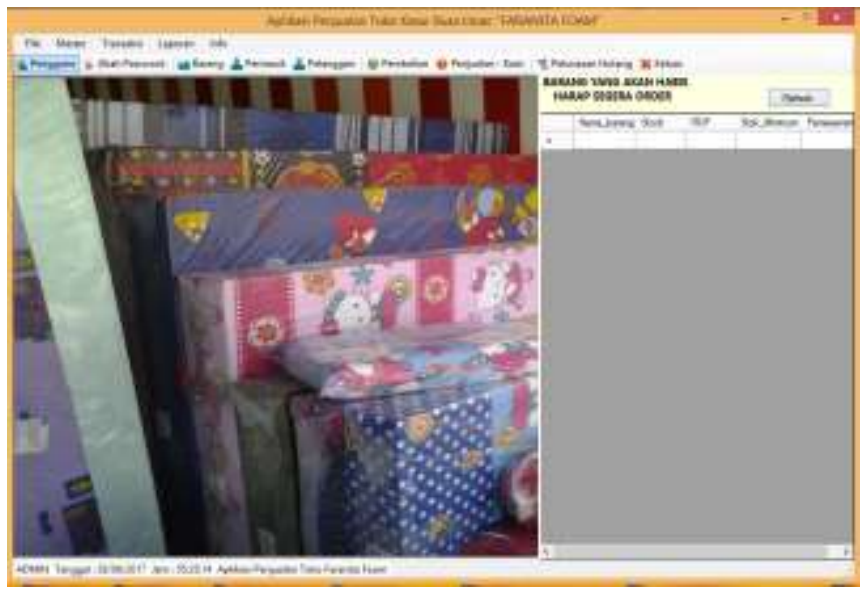

Gbr. 5 interface menu untuk admin 


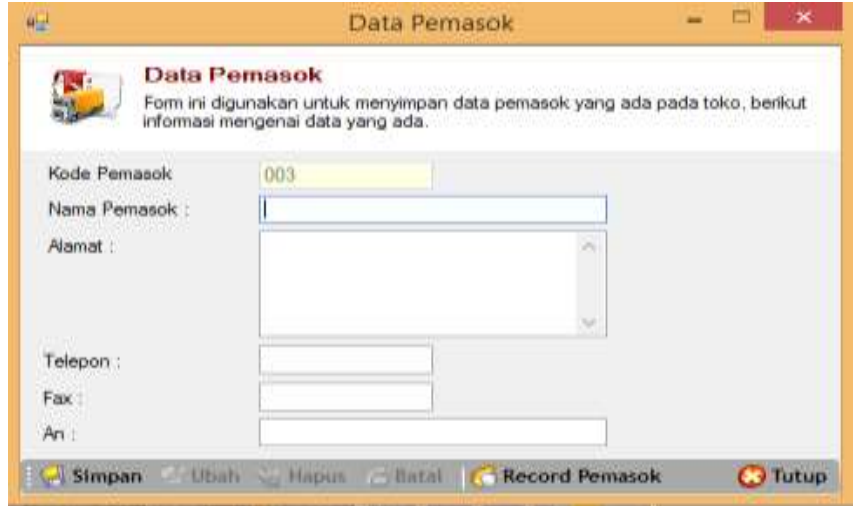

Gbr. 7 Form input data pemasok

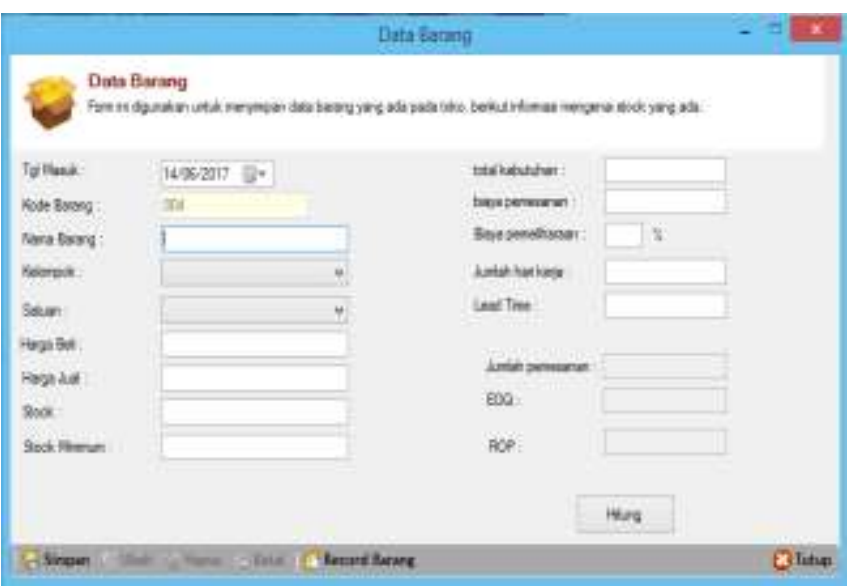

Gbr. 8 Form untuk input data barang

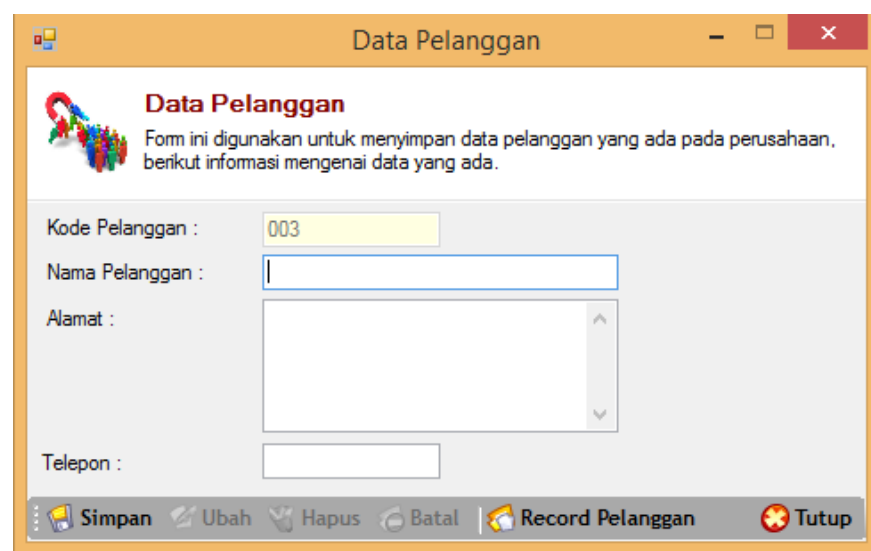

Gbr. 9 Form input data pelanggan

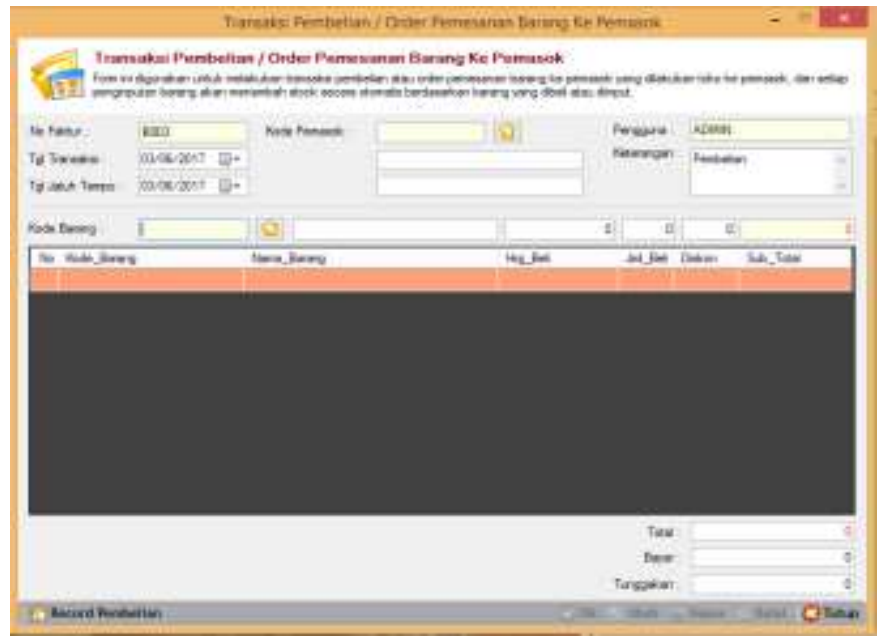

Gbr. 10 Tampilan transaksi pembelian

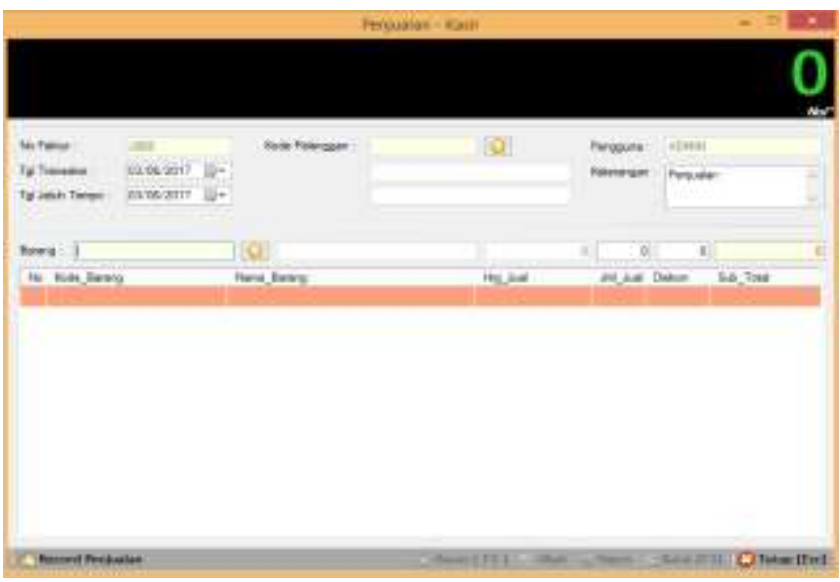

Gbr. 11 Menu tampilan penjualan

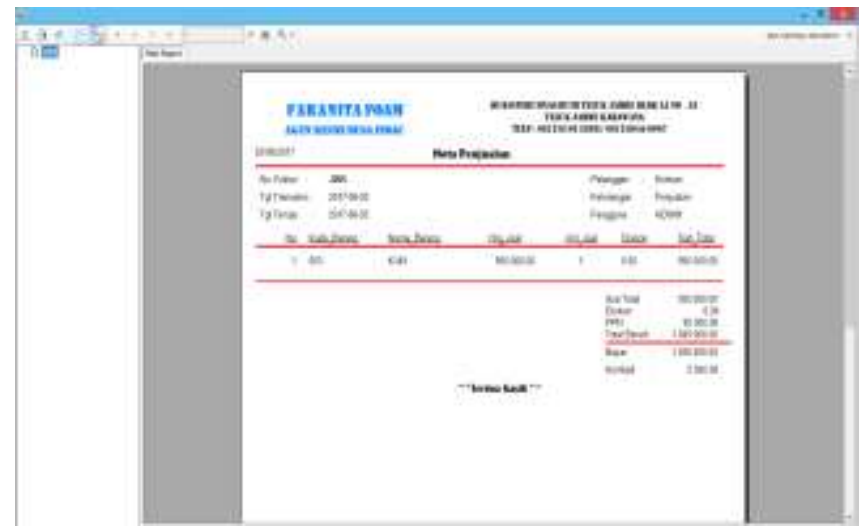

Gbr. 12 Tampilan Nota penjualan

Evaluasi penggunaan aplikasi point of sale dengan cara wawancara menggunakan teknik purpose sampling kepada pemilik toko, mencakup fungsi penyimpanan data, output laporan dan fungsi aplikasi dengan total pertanyaan sebanyak 20 pertanyaan. Evaluasi aplikasi terhadap pengguna yaitu semua menu dan tampilan aplikasi diujicobakan terhadap pengguna yaitu pemilik toko dan user/kasir untuk mengetahui sejauh mana fungsi - fungsi aplikasi dapat berjalan sesuai 
dengan tujuan perancangan aplikasi dan dievaluasi kembali oleh pengguna untuk mengetahui apakah aplikasi yang dibuat sudah cukup memenuhi kebutuhan atau belum. Dari hasil ujicoba terhadap pemilik toko dan kasir kemudian diwawancara diperoleh bahwa aplikasi Point of Sale dengan Metode Economic Order Quantity dan Reorder Point pada toko faranita foam $90 \%$ dapat diterima oleh pemilik toko dan $10 \%$ perlu dikembangkan kembali.

\section{KESIMPULAN}

Adapun kesimpulan yang didapatkan dari kajian metode Economic Order Quantity dan Reorder Point pada Aplikasi Point of Sale adalah pemilik toko memberikan penilaian kajian ini dapat membantu menyelesaikan dalam peninjauan pengelolahan data barang penjualan yaitu item kasur busa dan dapat digunakan sebagai penentuan persediaan barang sebagai stok agar tidak terjadi kekurangan atau kekosongan karena banyaknya pesanan kasur busa di toko bahkan pemilik tokopun dapat menggunakan perhitungan secara manual dalam analisis metode EOQ sampai ke RoP jika terjadi problem pada komputer tempat terinstalnya aplikasi.

Kajian Point of Sale dengan metode Economic Order Quantity dan Reorder Point pada aplikasi dilakukan dengan metode yang diterapkan dapat melihat record data barang serta notifikasi waktu pemesanan kembali dapat dilihat pada menu utama. Implementasi metode yang diterapkan dapat berjalan sesuai dengan yang diharapkan oleh pemilik toko Sehingga pengelolaan transaksi dan persediaan barang serta keuntungan toko tersebut bisa di dapat secara optimal.

\section{UCAPAN TERIMA KASIH}

Terima kasih penulis kepada pihak yang membantu ataupun memberikan dukungan terkait dengan penelitian yang dilakukan seperti bimbingan content dan teknis oleh para dosen pembimbing, dukungan para staff akademik dan pihak Toko Faranita Foam sebagai tempat penelitian dan kepada semua panitia pengelola journal JPIT atas semua bantuan dan dukungannya.

\section{DAFTAR PUSTAKA}

[1] S. Nurhayati and A. Elly, "Jurnal Pari Terbitan Bibliografi Sebagai Alat Bantu Penelusuran Informasi Di Kelautan Dan Perikanan Bibliography As An Information Search Tools At The Socio Economic Research Center Of The Marine And Fisheries Library," Vol. 2, 2016.

[2] I. Dan, P. Pindu, S. Fatimah, and H. Cangara, "The Use of Communication Channels in Obsorption The Community Aspirations by The Information and Government of Pinrang Regency," vol. 5, no. $1,2016$.

[3] A. P. Romanov, F. Kartika, S. Dewi, T. Adi, and P. Sidhi, "LocationBased Service Pada Aplikasi Pemesanan Cokelat Untuk Pengelolaan
Stok dan Pemantauan Merchandiser," pp. 141-150, 2017.

[4] T. Susanto and R. Marco, "Pengembangan Dan Rancang Bangun Teknologi Rfid ( Radio Frequency Identification ) Guna Optimalisai Stok Pada.'

[5] D. Kartikasari, "Baku Methanol Antara Pendekatan Model Economic Order Quantity Dengan Just In Time Pada Cv Mamabros,” no. 7 , 2014.

[6] D. P. Sari, S. Prodi, M. Bisnis, F. Ekonomi, and U. Telkom, "Analisis Pengendalian Persediaan Pos Dan Scanner Pada Bisnis Retail It Solution Di Pt . Kahar Duta Sarana Cabang Bandung Pada Tahun 2013 Inventory Control Analysis Of Pos And Scanner In Retail Business It Solution at PT . Kahar Duta Sarana Branch Bandung 2013,” 2013.

[7] T. M. Karanganyar, "Aplikasi penjualan barang secara multiuser pada distro thinker matesih karanganyar," pp. 39-44.

[8] B. Sudarsono, "Perancangan Program Sistem Informasi Persediaan dan Penjualan Barang Pada Toko Sparepart Motor,” pp. 35-39, 2017.

[9] L. J. Industri, E. Febryan, P. Sri, H. Eko, W. Valentinus, R. Hananto, and J. Vol, "ISSN 2338-137X Rancang Bangun Aplikasi Pengendalian Persediaan Bahan Baku Dengan Metode Economic Order Quantity Pada PT Gemah Ripah ISSN 2338-137X,” vol. 5, no. 11, pp. 1-8, 2016

[10] S. Pada, P. T. Daya, K. Cmi, N. Khalis, D. W. Prabowo, and U. D. Ali, "Sistem Informasi Inventory Dan Transaksi Sampit Berbasis Dekstop Java Netbeans dan MySQL," pp. 1-6.

[11] C. Yuliana, N. Sudjana, F. I. Administrasi, and U. Brawijaya, "Penerapan Model EOQ ( Economic Order Quantity ) Dalam Rangka Meminimumkan Biaya Persediaan Bahan Baku ( Studi Pada UD Sumber Rejo Kandangan-Kediri )," vol. 36, no. 1, pp. 1-9, 2016.

[12] R. H. Teunter, A. A. Syntetos, and M. Z. Babai, "PT US CR," Eur. J. Oper. Res., 2016.

[13] R. M. Vandawaker, D. R. Jacques, E. T. Ryan, J. R. Huscroft, and J K. Freels, "Journal of Quality in Maintenance Engineering Article information: To cite this document :," 2017.

[14] L. Cheng, C. Tsou, and D. Yang, "Cost-service tradeoff analysis of reorder-point-lot-size inventory models," J. Manuf. Syst., 2015.

[15] M. B. Kemokai, "An Analysis Of Logical Consistency In The Application Of Lean Techniques To Improve Business Processes And Service Delivery: A Case Of Department Of Field Support ( DFS ), United," vol. 1, no. 2, pp. 1-27, 2017.

[16] T. Rafliana, B. Suteja, " Penerapan Metode EOQ dan ROP untuk Pengembangan Sistem Informasi Inventory Bengkel MJM berbasis Web" Jurnal Teknik Informatika dan Sistem Informasi, vol. 4, nomor 2, p-ISSN: 2443-2210, e-ISSN: 2443-2229, Agustus 2018

[17] T. Iqbal, D. Aprizal, M. Wali, and U. S. Kuala, "Aplikasi Manajemen Persediaan Barang Berbasis Economic Order Quantity ( EOQ )," vol. 1 , no. $1,2017$.

[18] K. Nissa and M. T. Siregar, "Analisis Pengendalian Persediaan Bahan Baku Kain Kemeja Poloshirt Menggunakan Metode Economic Order Quantity ( EOQ ) Di PT Bina Busana Internusa,” vol. 1, pp. 271-279, 2017.

[19] F. Nurcahyono, "Pembangunan Aplikasi Penjualan Dan Stok Barang Pada Toko Nuansa Elektronik Pacitan," vol. 4, no. 3, pp. 15-19, 2012.

[20] T. Lukmana, D. T. Y, S. Jurusan, T. Informatika, and U. Kristen, "Penerapan Metode EOQ dan ROP ( Studi Kasus: PD . Baru )," J. Tek. Inform. dan Sist. Inf., vol. 1, pp. 271-279, 2015.

[21] N. Rosmawanti, "Optimasi Pengendalian Persediaan Bahan Baku Dengan Analisis Reorder Point," J. Tek. Inform. dan Sist. Inf., pp. 1187-1198, 2017

[22] U. Salesti, Jayana (Fakultas Ekonomi, “Analisis Penerapan Metode Economic Order Quantity Pada Persediaan Bahan Baku: Studi Kasus PT Imeco Batam Tubular Tahun 2014,” J. Meas., vol. 8, no. 3, pp. 2131,2014 